\title{
Review of Pharmacy Professionals and Drug Jurisprudence to Achieve the Millennium Development Goals in Punjab Province of Pakistan
}

\author{
Taha Nazir ${ }^{*}$, Azharul Islam² ${ }^{2}$ Nida Taha ${ }^{3}$, Saeed Urasheed Nazir ${ }^{4}$, Muhammad Ather Chaudhary ${ }^{5}$ and \\ Muhammad Iqbal ${ }^{5}$
}

\begin{abstract}
${ }^{1}$ University Medical \& Research Centre (UMDC), Biochemistry, Chemical Pathology, Molecular \& Microbiology Research Group, University Medical \& Research Centre, University of Sargodha, Sargodha 40100 Pakistan.

${ }^{2}$ VIDO-Inter Vaccine and Infectious Disease Organization-International Vaccine Centre (VIDO-InterVac), University of Saskatchewan, SK, Canada.

${ }^{3}$ Research \& Publication Division Intellectual Consortium of Drug Discovery \& Technology Development Incorporation, Saskatoon SK Canada S7L3E4.

${ }^{4}$ Department of Pharmaceutics Faculty of Pharmacy, University of Sargodha, 40100 Sargodha, Pakistan.

${ }^{5}$ Office of Research, Innovation and Commercialization (ORIC) Offices of Research, Innovation and Commercialization, University of Sargodha, 40100 Sargodha, Pakistan.
\end{abstract}

\begin{abstract}
The current health practice of Punjab Province of Pakistan needs a serious attention to control the unnecessary drug usage, improve pharmaceutical care and establish excellent public health system. Hence, the health officials of Govt. of Pakistan have established "Drug Regulatory Authority", and Punjab Health Department has chalked out Punjab Drug Rule, 2007 to deployed a revised health structure in Punjab. But, unluckily, the medical physicians, drug store owners and bureaucracy have not put it into actual practice. Punjab Health Department has made amendments in the Drug Rules, 2007; substituted the word "three" by the "ten" and suspended it until 2017 via notification printed in the official weekly gazette dated February 10, 2010. This potential confliction of interest can also be noticed in hospital settings, community clinical practice and other allied health institutions. The most awful part the current scenario is the insufficient aspirations to share the clinical burden to provide the health facilities for patients presented in hospital/ clinical setting. The consultant physicians and medical practitioners are very much reluctant to involve the pharmacy professionals to perform their primary professional role. They want them to stay away from their actual scientific job and keep doing the administrative and clerical work. Therefore, the current health system and drug jurisprudence needs a serious attention to address the health problem. That will help to minimize avoidable mortalities, wrong medication, irrational prescription and development of drug resistance. Moreover, a conclusive prescribing guidelines and appropriate drug jurisprudence will expedite the achievement of MDG of WHO.
\end{abstract}

Key words: Drug resistance, Millennium Development Goals, Drug rule, Pharmaceutical care, Clinical pharmacy.
Submission Date : 08-05-2015 Revision Date : :15-07-2015 Accepted Date : :19-07-2015

DOI: 10.5530/ijper.50.1.4 Correspondence Address Dr. Taha Nazir

Biochemistry, Chemical Pathology, Molecular \& Microbiology Research Group, University Medical \& Research Centre, University of Sargodha, Sargodha-40100 Pakistan. EMail:

taha.nazir@uos.edu.pk

\section{BACKGROUND}

After the partition of subcontinent, in 1947 Indian Muslims got an independent state of Pakistan. That was broke out, leading to the separation of East Pakistan (now Bangladesh) because of poor governance, political conflicts and violent military operation in 1971. ${ }^{1}$ A massive people were displaced, particularly the children, women and families affected second time after 1947. That posed a potential health hazards. Moreover, the "war on terror" that arose after the 9/11 attacks, forced many people of tribal areas

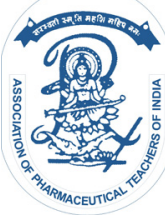

www.ijper.org 
and Afghanistan to migrate from the affected areas. As a result, $\geq 2,000,000$ people were displaced, 234,589 people forced to live in refugee camps and 2087160 individuals shifted outside the camps in rented accommodations or host families. Particularly, the women and children made up a large share of the Internal Displace People (IDPs). In addition of that, Pakistan was hit by natural disaster in 2005 and 2010. This first severe earthquake made $\geq 80000$ dead and millions of displacement. Then heavy floods with a dead toll of $\geq 2000$ people and 2,000,000 indirect victims pose serious health threats for local and international health organizations. The role of pharmacist in clinical setting is very poorly recognized as compared to other health professionals in Pakistan. Hence, the pharmacy profession lacks an interface in society and is still in developing phase. $^{2}$ The pharmaceutical care and process through which the medication delivered to the patients does not comply with the international standards to assure the safety. However, the pharmacies are licensed by Executive District Officer (EDO) on behalf of the Health Department, Government of the Punjab, Pakistan. The outlets are registered with the certificate of registration, but the quality of clinical and/ or pharmaceutical care has been reported to be poor. ${ }^{3}$ We are lacking the major components of patient's pharmaceutical care i.e. prescribing, administering, documenting and reviewing the drug usage. Whereas, the patient's counseling, therapeutical consultation and prevention of medication errors are potentially needed to improve the overall pharmaceutical care. Moreover, the current health care system is missing the drug information, utilization and selection. That may potentially help to rationalize the therapy plans, handle the disease state management and apply the Electronic Data Processing (EDP). In addition of that, tertiary care hospitals, teaching institutions and other clinical settings can improve their services by offering standards pharamcovigilance, pharmaco-economics, therapeutical monitoring, bio-safety, drug informations, and aseptic dispensary in Pakistan's Punjab. Unluckily, the major part of pharmacy graduates are employed in pharmaceutical production and very limited percentage join the community pharmacy practice in Pakistan. Whereas, in community pharmacy practice the standard health care facilities are not offered appropriately. The pharmacies are controlled by diverse types of pharmacy technicians and dispensers in terms of their knowledge, qualification and experience. Although the licensing requirement, the persons usually found managing pharmacies are often salesmen, owners or clerks, but not the licensee pharmacist. Even in the physical presence of the licensee or pharmacist, patients are often unlikely to reach the phar- macist. Instead, they are mostly attended by nontechnical salesman. In legitimacy, these pharmacies generally are registered by hiring a pharmacist, but in reality, they only rent a pharmacist degree or category-A registration license. ${ }^{4}$ The diploma holders in pharmacy, assistants pharmacists, pharmacy technicians and/ or dispensers are responsible to work as storekeeper, accountant, inventory manager, a dispenser, patient counsellor and information provider. ${ }^{5}$

Hence, the major challenges to Pharmacy practice to achieve the millennium development goals are multitudinous in versatile environments. The decision regarding the selection of medication is influenced by the biased source of information. That mainly is acquired from neighbouring pharmacies, physicians, job experience, suppliers, newsletters, magazines, internet and leaflets. ${ }^{6}$ The regulations regarding the drugs prescription are generally not respected. Even, narcotics, control and potent drugs are dispensed without appropriate procedure and recording the patient's informations. The drug sellers hardly ever ask questions to maintain patient's profile, record the illness, and obtained inadequate history to determine the severity or nature of disorder to assure the appropriateness of treatment. ${ }^{7}$ The' retail medical stores, drug stores, chemist shops, medicose or pharmacies are most convenient accessible places to get healthcare facilities in Pakistan's Punjab. ${ }^{8}$ They are very diverse in their role and setups. These can be noticed like market place around the public and private hospitals. Even some exist in the grocery stores. The attending customer patients usually come without an appropriate prescription. The technicians or dispensers are mostly observed working as pharmacist, physician, laboratory technicians and paramedics. ${ }^{9}$ Although, the drugs dispensing is a significant part of rational drug usage, but it has been ignored by researchers in Pakistan's Punjab. Very limited research work and intervening studies are available to explain the pharmacy practices in Pakistan. ${ }^{10}$ All literary work highlight the limited area dimensions, poor quality of premises, lack of dispenser's basic education and knowledge. That should ideally be improved to assure the targeted health care facilities and achievement of MDG's.

\section{Health care system}

There is a three tiered health care delivery system in Pakistan. That comprised of primary, secondary and tertiary care system. Health system strengthening mechanism start at grass roots level, ${ }^{11}$ health houses provide community health care services through Lady Health Visitors (LHV's) and are connected to basic health units with an upward referral pathway to Rural Health Centres, Tehsil Hospitals and District Hospitals. There are also well 
Table 1: Comparison of pharmacists yearly addition, gender (\%), population Vs pharmacist, $\%$ addition and yearly population growth of with last thirty four years early statistical analysis of pharmacist with gender distribution, pharmacist

\begin{tabular}{|c|c|c|c|c|c|c|c|c|c|}
\hline Year & $\begin{array}{c}\text { Yearly } \\
\text { addition }\end{array}$ & Yearly total & Male & Male \% & Female & Female \% & $\begin{array}{c}\text { Pharmacist } \\
\text { per } \\
1000000 \\
\text { population }\end{array}$ & $\begin{array}{c}\% \\
\text { Addition }\end{array}$ & $\begin{array}{c}\text { Yearly } \\
\text { population } \\
\text { growth } \\
(\mathrm{X100000)}\end{array}$ \\
\hline 1972 & 122 & 122 & 117.00 & 95.90 & 5.00 & 4.09 & 3.06 & - & 39.83 \\
\hline 1973 & 113 & 235 & 108.00 & 95.58 & 5.00 & 4.43 & 5.76 & 48.09 & 40.83 \\
\hline 1974 & 57 & 292 & 55.00 & 96.49 & 2.00 & 3.51 & 6.98 & 19.52 & 41.84 \\
\hline 1975 & 38 & 330 & 35.00 & 92.11 & 3.00 & 7.99 & 7.71 & 11.52 & 42.82 \\
\hline 1976 & 58 & 388 & 53.00 & 91.38 & 5.00 & 8.62 & 8.87 & 14.95 & 43.77 \\
\hline 1979 & 31 & 419 & 30.00 & 96.77 & 1.00 & 3.23 & 8.78 & 7.40 & 47.72 \\
\hline 1981 & 38 & 457 & 35.00 & 92.11 & 3.00 & 7.99 & 8.97 & 8.32 & 50.95 \\
\hline 1982 & 30 & 487 & 28.00 & 93.33 & 2.00 & 6.67 & 9.24 & 6.16 & 52.69 \\
\hline 1984 & 98 & 585 & 86.00 & 87.76 & 12.00 & 12.24 & 10.51 & 16.75 & 55.64 \\
\hline 1985 & 60 & 645 & 54.00 & 90.00 & 6.00 & 10.00 & 11.28 & 9.30 & 57.16 \\
\hline 1986 & 37 & 682 & 34.00 & 91.89 & 3.00 & 8.11 & 11.57 & 5.43 & 58.93 \\
\hline 1987 & 21 & 703 & 18.00 & 85.71 & 3.00 & 14.29 & 11.56 & 2.99 & 60.81 \\
\hline 1988 & 119 & 822 & 110.00 & 92.44 & 9.00 & 7.56 & 13.10 & 14.48 & 62.73 \\
\hline 1989 & 126 & 948 & 104.00 & 82.54 & 22.00 & 17.46 & 14.67 & 13.29 & 64.63 \\
\hline 1990 & 132 & 1080 & 105.00 & 79.55 & 27.00 & 20.45 & 16.23 & 12.22 & 66.54 \\
\hline 1991 & 70 & 1150 & 59.00 & 84.29 & 11.00 & 15.71 & 16.80 & 6.09 & 68.46 \\
\hline 1992 & 128 & 1278 & 109.00 & 85.16 & 19.00 & 14.84 & 18.26 & 10.02 & 69.98 \\
\hline 1993 & 100 & 1378 & 78.00 & 78.00 & 22.00 & 22.00 & 19.29 & 7.26 & 71.44 \\
\hline 1994 & 95 & 1473 & 76.00 & 80.00 & 19.00 & 20.00 & 20.12 & 6.45 & 73.22 \\
\hline 1995 & 112 & 1585 & 87.00 & 77.68 & 25.00 & 22.32 & 21.09 & 7.07 & 75.14 \\
\hline 1996 & 119 & 1704 & 84.00 & 70.59 & 35.00 & 29.41 & 22.06 & 6.99 & 77.23 \\
\hline 1997 & 55 & 1759 & 36.00 & 65.46 & 19.00 & 34.55 & 22.21 & 3.13 & 79.21 \\
\hline 1998 & 158 & 1917 & 106.00 & 67.09 & 52.00 & 32.91 & 23.63 & 8.24 & 81.14 \\
\hline 1999 & 256 & 2173 & 167.00 & 65.23 & 89.00 & 34.77 & 26.15 & 11.78 & 83.09 \\
\hline 2000 & 112 & 2285 & 78.00 & 69.64 & 34.00 & 30.36 & 26.77 & 4.90 & 85.36 \\
\hline 2001 & 256 & 2541 & 165.00 & 64.45 & 91.00 & 35.55 & 28.94 & 10.07 & 87.81 \\
\hline 2002 & 190 & 2731 & 117.00 & 61.58 & 73.00 & 38.42 & 30.43 & 6.96 & 89.75 \\
\hline 2003 & 244 & 2975 & 157.00 & 64.34 & 87.00 & 35.66 & 32.56 & 8.20 & 91.37 \\
\hline 2004 & 287 & 3262 & 160.00 & 55.75 & 127.00 & 44.25 & 35.04 & 8.80 & 93.09 \\
\hline 2005 & 571 & 3833 & 469.00 & 82.14 & 102.00 & 17.86 & 41.18 & 14.90 & 93.09 \\
\hline 2006 & 415 & 4248 & 271.00 & 65.30 & 144.00 & 34.70 & 44.01 & 9.77 & 96.53 \\
\hline 2007 & 467 & 4715 & 280.00 & 59.96 & 187.00 & 40.04 & 47.98 & 9.91 & 98.28 \\
\hline 2008 & 470 & 5185 & 263.00 & 55.96 & 207.00 & 44.04 & 51.88 & 9.07 & 99.95 \\
\hline 2009 & 697 & 5882 & 393.00 & 56.39 & 304.00 & 43.62 & 57.89 & 11.85 & 101.62 \\
\hline Total & 34 & 34 & 34 & 34 & 34 & 34 & 34 & 33 & 34 \\
\hline Mean & 173.00 & 1772.62 & 121.38 & 78.6050 & 51.62 & 21.4015 & 21.61 & 10.6630 & 70.67 \\
\hline Median & 116.00 & 1328.00 & 95.50 & 81.0700 & 20.50 & 18.9300 & 18.78 & 9.0700 & 70.71 \\
\hline $\begin{array}{l}\text { Grouped } \\
\text { Median }\end{array}$ & 115.00 & 1328.00 & 95.50 & 81.0700 & 20.80 & 18.9300 & 18.78 & 9.0700 & 70.71 \\
\hline $\begin{array}{l}\text { Std. Error } \\
\text { of Mean }\end{array}$ & 28.691 & 263.106 & 17.789 & 2.33114 & 12.127 & 2.33025 & 2.418 & 1.34306 & 3.289 \\
\hline Sum & 5882 & 60269 & 4127 & 2672.57 & 1755 & 727.65 & 735 & 351.88 & 2403 \\
\hline Minimum & 21 & 122 & 18 & 55.75 & 1 & 3.23 & 3 & 2.99 & 40 \\
\hline
\end{tabular}




\begin{tabular}{|c|c|c|c|c|c|c|c|c|c|}
\hline Maximum & 697 & 5882 & 469 & 96.77 & 304 & 44.25 & 58 & 48.09 & 102 \\
\hline Range & 676 & 5760 & 451 & 41.02 & 303 & 41.02 & 55 & 45.10 & 62 \\
\hline First & 122 & 122 & 117 & 95.90 & 5 & 4.09 & 3 & 48.09 & 40 \\
\hline Last & 697 & 5882 & 393 & 56.39 & 304 & 43.62 & 58 & 11.85 & 102 \\
\hline $\begin{array}{c}\text { Std. } \\
\text { Deviation }\end{array}$ & 167.295 & 1534.16 & 103.725 & 13.59275 & 70.712 & 13.58755 & 14.101 & 7.71527 & 19.178 \\
\hline Variance & 27987.636 & 2353645.880 & 10758.910 & 184.763 & 5000.183 & 184.621 & 198.850 & 59.525 & 367.782 \\
\hline Kurtosis & 2.406 & .661 & 3.669 & -1.368 & 4.220 & -1.367 & .325 & 17.778 & -1.185 \\
\hline $\begin{array}{c}\text { Std. Error } \\
\text { of Kurtosis }\end{array}$ & .788 & .788 & .788 & .788 & .788 & .788 & .788 & .798 & .788 \\
\hline Skewness & 1.712 & 1.189 & 1.895 & -.273 & 2.020 & .273 & 1.007 & 3.754 & -.054 \\
\hline $\begin{array}{c}\text { Std. } \\
\text { Error of }\end{array}$ & .403 & .403 & .403 & .403 & .403 & .403 & .403 & .409 \\
\hline Skewness & 81.07 & 736.02 & 68.15 & 76.1716 & 6.98 & 11.8017 & 13.68 & 8.1080 & 65.20 \\
\hline $\begin{array}{c}\text { Harmonic } \\
\text { Mean }\end{array}$ & 116.74 & 1185.30 & 90.37 & 77.4089 & 19.23 & 16.4835 & 17.44 & 9.1833 & 67.98 \\
\hline $\begin{array}{c}\text { Geometric } \\
\text { Mean }\end{array}$ & & & & & & & & & \\
\hline
\end{tabular}

equipped tertiary level teaching hospitals associated with medical/ health teaching institutions. However, this extensive health care infrastructure has not been translated into optimal health care delivery due to a number of issues related to the health system. ${ }^{12}$ This includes the poor motivation of the health workforce due to lack of good career structures and work environments, mal distribution of resources between urban and rural areas, and the lack of a national human resources for health policy. Only $0.5 \%$ of gross domestic product (GDP) is spent on health. That is very low and leads to an inability of the government to provide the required medicine and laboratory support to health care delivery resulting in an out-of-pocket expenditure on health of around $80 \%$. Furthermore, the miserable part of current scenario is the poor health information system, which does not produce the quality data required for planning. ${ }^{13}$

\section{Drug jurisprudence}

A strategic support for health care system may potentially help to improve the pharmaceutical care, clinical facilities and control the infectious superbugs in Pakistan. Whereas, the accomplishment of drug jurisprudence may also assure the rationalization of pharmacotherapy and clinical practice. We may than minimize the avoidable mortalities. Moreover, the therapeutical drug monitoring, pharmaceutical care and patient awareness/ counseling will play a key role to establish health standards and achieve the Millennium Development Goals (MDG's) of World Health Organization (WHO). Hence, the establishment, bureaucracy, civil society and health professional have to design a collective effort to assure the achievement of MDG's. Thus, Drug Act is enacted as primary legislation by a national or sub-national parliament to controlling individual or collective behavior. In commonwealth countries, the term is used both in a narrow sense, as the formal description of a law passed in certain territories, and in a wider sense for primary legislation passed in country. ${ }^{14}$ That can be taken in many forms: a) medico-legal restrictions promulgated by a government authority, b) self-regulation by a pharmaceutical industry through a trade association, c) social regulation, d) co-regulation and e) market regulation. One can consider regulation as actions of conduct imposing sanctions. Hence; administrative drug law, or implementing pharmaceutical regulatory law, may be contrasted with statutory or case law. The regulations, policies and ordinance are enforced to optimize the health practice, clinical and/ or pharmaceutical care. ${ }^{15}$ The health professional and regulatory authority works to resolve legal discrepancies, correct clinical care and assure the safety of patients. That collaborate the individual and institutional working and provide standard guidelines for health professionals.

Drug Act, 1976 was promulgated on $11^{\text {th }}$ May, 1976 in Pakistan to regulate the drug administration, enforcement, prohibition, offences, penalties and procedures. There were certain pharmaceutical discrepancies; drug related complication and worldwide changes in health scenario has posed potential challenges. That needs an accurate and urgent response. Hence; the pharmaceutical professionals and drug experts work hard to provide high quality legislation Punjab Drug Rule, 2007. The Governor of the Punjab, Pakistan has notified this Punjab Drugs Rules 2007 under section 44 of the Drugs Act 1976. The rules were revised after a gap of 19 years. Under this rules, the licensing authority will issue the drug sale license on basis of the report of the drug 


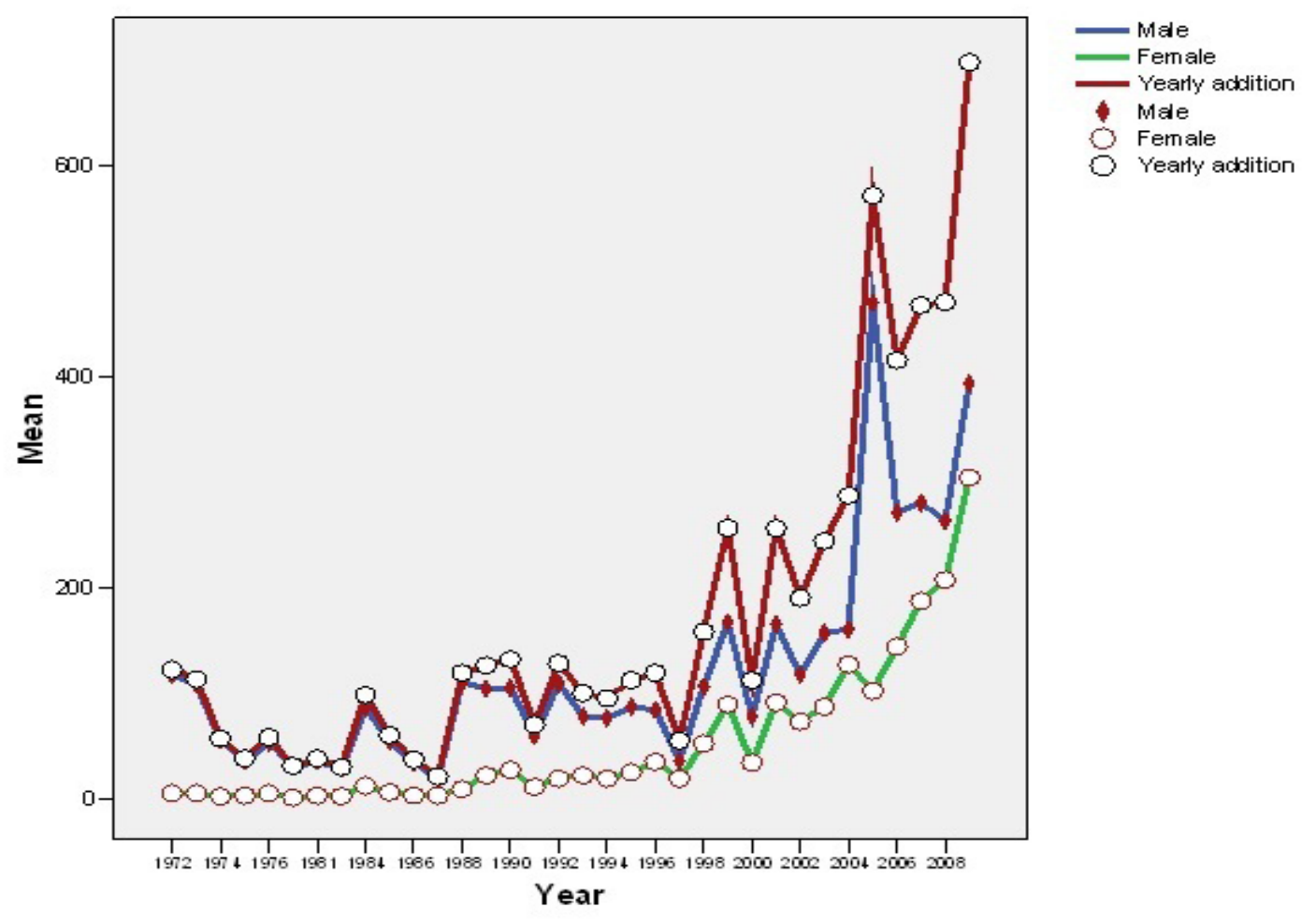

Figure 1: Chronological review of male, female and yearly addition of pharmacists during last thirty four (34) years; 1972-2009; in Punjab province of Pakistan

inspection of that area of jurisprudence to make sure the clean and hygienic premises of a pharmacy or medical store, adequate facility for storage of drugs and for their protection from direct sunlight and dust. Moreover; the period of renewal of the license reduced from two to one year. Particularly; these rules barred the drug store that not hired the pharmacist for the purpose of pharmaceutical community services to sell a total one hundred and forty five (145) life-saving controlled, narcotics or potent drugs. It is enforced to accomplish with the internationally accredited standards and provide quality health services. It becomes especially important to promote the rational drug usage and encourage pharmacy culture in Punjab province of Pakistan. Hence; in this way approximately 50,000 drug stores in Punjab are requested to comply with the internationally accredited criteria to improve the health standards in province. Furthermore; a nine-member Provincial Quality Control Board (PQCB), headed by the provincial health secretary, has been constituted. The board may constitute a committee in a district to be known as the district quality control board. Both boards may meet at least once a month to review the situation of drugs' quality control. Before referring a case to a drug court, the provincial or district board shall ascertain the name of the director, partner, and employee of the company who is prima facie responsible for the commission of the offence under the Act or rules and may allow an inspector to institute prosecution against such person. According to the rules, no person shall be appointed as an inspector unless he holds a degree in pharmacy from a university or an institution recognized by the Pharmacy Council of Pakistan and has at least one-year experience in manufacture, sale, testing and analysis of drugs.

\section{Punjab Drug Rule, 2007}

\section{Clinical and pharmaceutical Role}

The health system of Pakistan lacks the appropriate clinical and pharmaceutical services. The major components of pharmaceutical care; patient counseling, prescription review, therapeutical drug monitoring have not been correctly included in health care system of the province. The role of pharmacist has not been officially notified in hospital and clinical settings. Hence; the drug experts or pharmacists are intentionally (or may be unintentionally) placed into non-professional administrative and managerial positions. The more terrible part of this scenario is the absence of ambitions and potential to correct the role of qualified pharmacist. The role of pharmacist has been modified worldwide. He supposed to be more responsible to review and correct the dose, ${ }^{16,17}$ regimen, therapy plan and treatment protocols to assure quality health services. The new $\mathrm{z}$ 


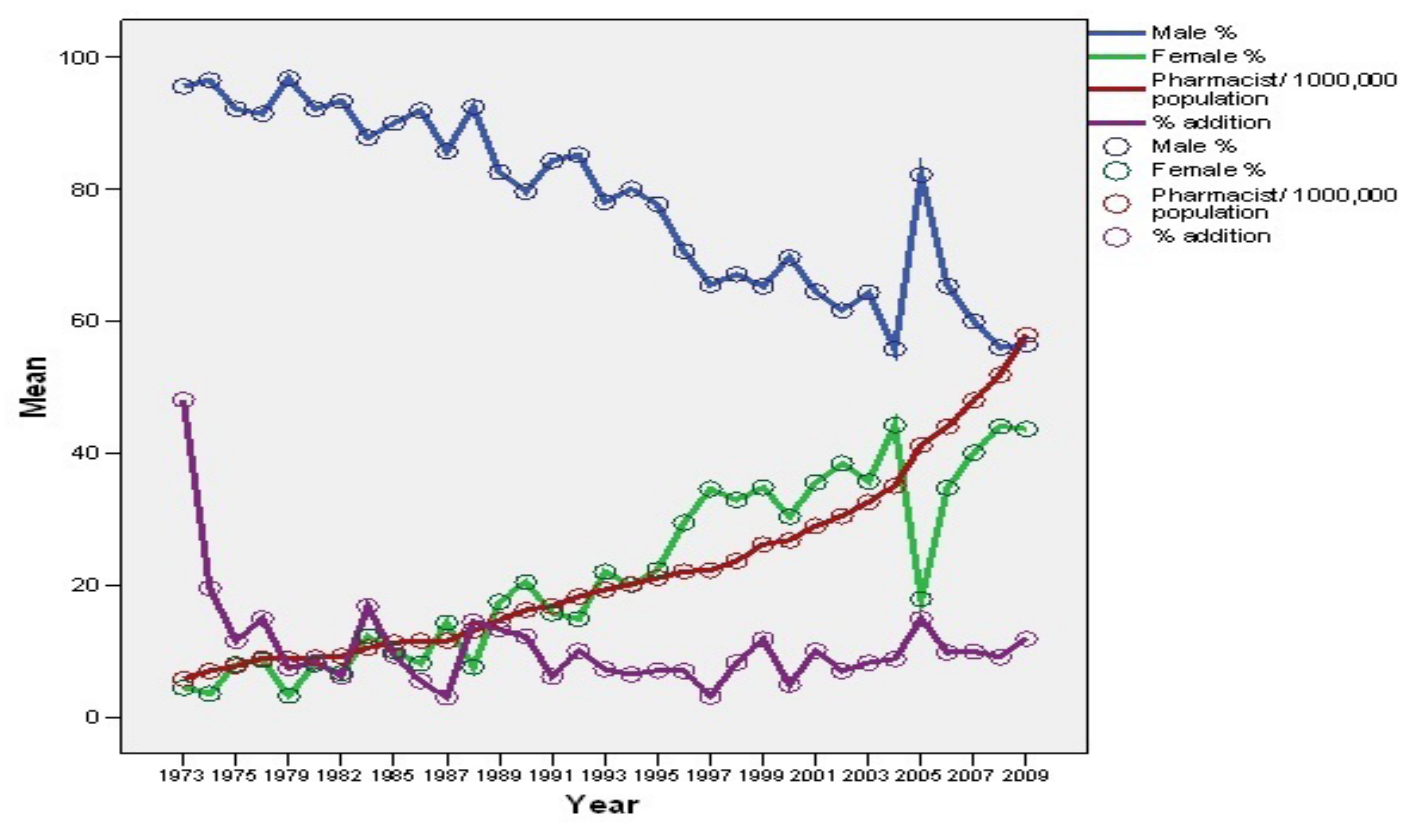

Figure 2: Comparison of male (\%), female (\%), pharmacist/1000,000 population and \% addition of pharmacists with time (last thirty four years) 1972-2009; in Punjab province of Pakistan

\section{Pharmaceutical Profession Intervention}

There are very limited numbers of chemist shops in Pakistan offering the patient counseling, guidance and information facilities. There are not proper arrangements to guide the patient regarding the therapeutical, clinical and pharmaceutical information of drug and disease. Especially; the professional intervention of pharmacist produces a compatibility of drugs with the patient's medical profile, ${ }^{10}$ social constraints and personal obtained data. Thus; Punjab drug Rule 2007 endows professional services along with the coverage enforcement worldwide accepted clinical services.

\section{Control over the Potent and Control Drugs}

Drugs are quite different than food, grocery, appliances and daily utensil. These are delivered in an appropriate scientific way with standard procedure to avoid any health hazard. ${ }^{11}$ But unluckily; there in no control over the potent drugs to assure health services. A clear distinction of over the counter drugs and scheduled drugs are described under this Punjab drug rule, 2007. These definitions also referred as schedule $G$ drugs.

\section{Suspension of Drug Rule 2007}

The drug rule 2007 was suspended by Governor Punjab, Pakistan because of some ambiguous reasons. The secretary to the Governor of the Punjab has issued notification by the order of the governor of the Punjab; printed in the Punjab weekly gazette dated February 10, 2010, page No. 951. In exercise of power conferred upon him under Section 44 of the Drug Act. 1976 (XXXI of 1976) which empower government to make rules under Act subjected to previous publication. The governor of the Punjab has made amendments in the Punjab Drug Rules, 2007 after previous publication of these amendments. In rule 1 , sub rule (3) for the word "three" is substituted by the word "ten". Thus the drug rule enforced in 2007 and supposed to be fully implemented in July, 2010 is now enforced in 2017. The enforcement is delayed because of the arguments as under;

- There are no sufficient numerical pharmacists available to place at each and every drug stores of province. This rule may affect about 50,000 drug stores in Punjab province of Pakistan. ${ }^{4}$

- Current health system needs such practice to serve the non-affording community; particularly in rural areas of the province.

- Pharmaceutical business organizations (retail medical stores, wholesale drug stores, pharmaceutical distributers etc) of province can't afford the minimum salary package that could be offered to qualified registered category-A pharmacists.

- Current health structure can't match with standard addressed in Punjab Drug Rule, 2007.

- The attitude of civil society, individual behaviors of patients and official bureaucratic structure having insufficient potential to enforce the changes. 
- That may cause a big trouble for patients' maintain a regular therapy of diseases i.e. diabetes, hypertension, AIDS, gout, allergy etc.

- Unclear role of wholesalers and distributors.

Thus; the chemist association has not accepted this rule and protest the government to withdraw/ delay implementation. The pharmaceutical merchandisers, manufacturers, druggists and chemist associations are working effectively to preserve their privilege of gigantic profit, legal exemptions and untrained working practice. This potential confliction of interest can be noticed in community pharmacies, hospital settings and official health institutions. The business community is seemed to be dominant over skilled, qualified and professionally competent drug experts or pharmacists. They have excellent resources, efficient political influence, good team work and loyalty with their violation.

\section{Impact of suspension of Drug Rule 2007}

Punjab Drug Rule, 2007 was an important document for society, health professional and pharmaceutical business community. That may impact the community pharmacy practice, pharmaceutical supplies and official procurements. The physicians and pharmaceutical companies also like to change the rule to establish a harmony. The over impact of Punjab Drug Rule, 2007 is as under;

\section{Community Pharmacy practice}

The actual role of pharmacist may introduced by the enforcement of drug rule 2007. As the drug rules 2007 has reduced the period of renewal of drug sale license from two to one year. The licensing authority also not probably issues the license without the consent of drug inspector. The drug rule 20 (1) (e) says: "A licensee of a medical store shall not sell or store a drug mentioned in the schedule G". The drugs included in this schedule are; for anti-leprosy - Rifampicin Injection, Dapsone, Clofamazine, Ethionamide and Prothionemide, for immunological products, vaccines, sera $\backslash$ ant-sera - Vaccines of Anthrax, BCG, Botulisms Antitoxin, Cholera, Influenza, Measles, MMR, Rubella, Pneumococcal, Poliomyelitis, Smallpox, Typhoid, Rabiies and Homophiles Influenza Type B, and Immunoglobulins, for products related with malignant diseases and immunosupression - Folinic Acid, Doxorubicin HCI, Mercaptopurine, Thioguanine, Vincristine, Cisplastin, Busulphan, Carmustine, Lomustine, Cyclophosphamide, Melphalan, Fluorouracil, Mitozantrone, Methottrexate, Vinblastine, Carboplatin, Bleoimycin, Chlorambucil, Dacarbazine, Amasascrine, Azathioprine and Cyclosporin - for anesthesia and inhalation anesthetics - Propofol, Enfluran, Isofluran, Halotha ne, Bupivacain, Thiopentone, Benzodiazepine, Mitazolam, Naloxone Hcl, Vancuronium, Pancuronium,
Tubocuraine, Suxamethonium and Neostigmine - for antibiotics - Spectinomycin, Teicoplanon, Sodium Fusidate, Vancomycin, Colistin and Impenem - for inotropics - Primacor, Enoximone and Milrinone - for injection prostaglandins - Dinoprotone, Gemeprost AND Carboprost - for alpha blocker - Prazosin Hcl, Daxazosing, Indramine and Alfuzosin - for biotechnological products - Interferon and Erythropoetin - for narcotics, psychotropic and tri cyclic ant-depressant - Morphine, Buprenorphine, Nalbuphine, Fantanil, Pethidine, Lorazepam, Temazepam, Chlorpromazine, Melprobamate, Chlordiazepoxide, Alprozolam, Clonazepam, Flurazepam, Loprazolam, Oxazepam, Amoxapine, Iprine Dole Codine, Pentazocine, Lithium, Dextropropoxyphene, Clomipramine, Mianserin, Maprotiline, Dothiepin, Doxepin, Nortriptyline, Trimiprammine, Tranycypromine, Flupenthixol, Tryptophan, Imipramine and Amipriptyline - for anti-viral - Acyclovir, Amantadine Hcl, Famciclovir, Inosine Pranolsex, Zidovudine, Ganciclovir, Idoxuridine, Riavirin, Vidarabrin, Trifluridine and Methisozone - for thrombolytic enzymes - Alteplase, Streptokinase, Anislreplase and Urokinase - for dialysis - Peritoneal, Haemodialysis, Hyper tonic solution, Lysine solution and Isotonic solution - for creams and aerosols steroidal preparations Methylprednislone, Dexamethasone, Hydrocortisone, Prednisolone, Tramcionolone and Beclomethasone for hormones - Vasopressin, Desmopressin, Stanozolol, Nandrolone, Mesterlolone, Finasteride, Finasteriode, Somatropin, Testosterone and Progestrogens.

The administrative function of pharmacist most probably is converted into his actual professional role required by the system. Responsibilities of pharmacist will become more versatile and critical. ${ }^{18}$ Presently drug sale license is awarded to pharmacist assistant, category-B holders and pharmacy technicians and will be declined. As the pharmaceutical merchandisers hire the degree (or his Category A) and pay Rs1,000-10,000 per monthly or yearly basis, depending upon agreement reached or understanding between two parties.

\section{General physician practice}

Presently the marketing strategies of considerable number of pharmaceutical companies do not qualify the moral criteria. The unethical promotion schemes award sufficient benefits to physicians in the form of renovating the clinics, gifting expensive equipments, providing home appliances (from juicer machine to motor car), offering the printing/ stationary facilities, financing for touring abroad, funding for diners and extending the limits of courtesy by paying their utility bills. Moreover; some companies offered the hard cash commission for successful achievement of the agreed sale targets. This 
criminal understanding might be disturbed by enforcing the Punjab drug rule 2007. Therefore; their representing body the Pakistan Medical Association (PMA) has recorded the protest in Lahore on Wednesday, August 01, 2007. They rejected the Punjab Drug Rules 2007 and said that amendments were not favorable for people. In a press release, PMA General Secretary and Finance Secretary said the amendments in the Punjab Drug Rules 2007 would promote nepotism. Few affluent people would get benefit while thousands of medical stores would be closed down. Furthermore; the PMA officebearers criticized the government for not implementing the Punjab Drug Rules 1988 in its true spirit and alleged that the drug mafia had brought about these amendments with the connivance of drug inspectors to spread its business across the Punjab. They demanded that the government abrogate the amendments in the best interest of the people.

\section{Clinical pharmacy practice}

A standard clinical pharmacy practice offer drug information, quality medicines, pharmaceutical care, comprehensive knowledge of treatment ${ }^{19}$ and therapeutical skills. Being a part of clinical practice; pharmacy is the rapidly growing discipline of health sciences. Therefore; Punjab drug rule 2007 facilitate its implication and rationalize the scientific approach. The basic apprehensions of this segment of pharmaceutical care are to understand the chemotherapy protocols, accuracy of regimens and professional obligations. The overwhelming scientific information explosively changing the usual concepts regarding the mechanism, bioavailability and half life that ultimate have introduced the new therapeutical orientation; pharmacogenetic, pharmacometrics and pharmacodynamic. ${ }^{20}$ It is therefore particularly tried to clear scientific conceptual ambiguities.

\section{Pharmaceutical merchandisers}

The whole sale or massive uncontrolled selling of pharmaceuticals is the major source of unnecessary drug usage and poor clinical practice. ${ }^{21}$ There are so many protests of chemist associations recorded during last five years. In Multan, Aug 12, 2007 chemists held a protest demonstration against Punjab Drug Rules 2007 at Clock Tower Chowk. The protesters led by Multan Wholesale Chemists Council and blocked the road and chanted slogans for the withdrawal of rules. Speaking on the occasion said the new regulations would be economically disastrous for chemists. They would not accept one-sided amendments to drug rules. The Punjab government had changed the drug rules without consultation. They would set up huger-strike camps and hold demonstrations in each city of Punjab till the withdrawal of the new regulations. Selling the life saving drugs by the way of whole sale has imposed hazardous effects as under; 1). The regulatory control over the narcotics and potent drugs (benzodiazepines, opiate alkaloids, vaccine, anticancer, tranquilizers) undermined. 2). The chances of breaching of the cool chain increased. Thus; the over or under temperature preservation deteriorate the efficacy of drugs. 3). Record keeping, invoicing, warranting and regularizing the inventory become ambiguous and difficult. 4). Chanced of introduction of substandard, non-warranted, spurious and misbranded increased. Thus; the overall quality of pharmaceutical care and health standards deteriorated. 5). The present whole sale business procedures in Pakistan; Lohari market Lahore, Bohar Bazar Rawalpinidi etc is totally wrong practice as per criteria of health sciences. These are places for smugglers, rule violators and corrupt merchandisers. Such places and business kinds supply the illegal, banned and withdrawn drugs directly into the society through the quacks, dispensers (category B holders or pharmacy technicians), retailers (having drug sale license without hiring services of pharmacist).

\section{Potential risk factors}

The potential risk factors of Punjab drug rules 2007 are included in either sense of the business damages, extra pharmaceutical legal restrictions, limited health product ranges and hiring specific skilled workforce. While in other way; the benefits are include the business improvement, exemptions of the legal restrictions, extension of the business size and running company with raw handed workers. The rapidly growing pharmacist community was excited for getting the chance to prove their professional expertise. They were ambitious to exhibit their all theoretical learning's into actual pharmaceutical practice. A total more $\geq 6000$ registered with the Punjab Pharmacy Council and $\geq 3000$ graduating pharmacists in Pakistan definitely wish to improve their professional worth. In other way; the raw workers and pharmaceutical business merchandisers strive to grab gigantic profit, exemptions from the legal restrictions, improvement of business size/ range with untrained workers. This confliction of interest can be observed in national/ provincial assemblies, health departments, pharmaceutical market places (Lohari market Lahore, Bohar Bazar Rawalpindi etc) and academic institutions. The professional struggle of pharmacist community is not effectual because of the lack of the mandated leadership and influence of government officials over conclusive procedures. Moreover, the individual pharmaceutical professional bodies don't have common agenda and professionally preferred objectives. 
Whereas; the efforts of business community are more effective, collective and successful. ${ }^{22}$ They have more reliable political connections, better financial resources and excellent professional commitments. Hence, the current pharmaceutical situation and drug jurisprudence need attention to establish a balanced clinical and health care system. ${ }^{23}$ That may potentially improve the public health and assure the achievement of MDG's in Punjab Province of Pakistan.

\section{CONCLUSION}

Current health system needs serious attention to address the potential health problem in Punjab province of Pakistan. A prospective jurisprudential support may help to improve the clinical and pharmaceutical care. Moreover, there is an insufficient aspiration in health officials to assign the more relevant, professional and clinical role i.e. dose correction, regimen rationalization, prescription review, patient counseling, therapeutical drug monitoring to pharmacy professionals, instead of current clerical and administrative work. Additionally; the pharmacacovigilance, ADR's, pharmacoecnomics and pharmacometrics should also be implicated to achieve the MDG's of World Health Organization.

\section{ACKNOWLEDGEMENT}

The authors acknowledge the kind support of Muhammad Shamoon Chaudhary, Secretary Punjab Pharmacy Council and Prof. Dr. Nadeem Irfan Bukhari, University College of Pharmacy, University of the Punjab, Lahore, Pakistan.

\section{CONFLICT OF INTEREST}

The authors declare no conflict of interest.

\section{ABBREVIATIONS}

DRAP : Drug Regulatory Authority of Pakistan.

PCP : Pharmacy Council of Pakistan

HEC : Higher Education of Pakistan

DTL's : Drug Testing Laboratories

EDO's : Executive District Officers

BEMS : Bachelor of Eastern Medicine \& Surgery

BHMS : Bachelor of Homeo Medicine \& Surgery

PPA : Pakistan Pharmacists Association

\section{SUMMARY}

- Description of most current situation of pharmacy profession in Pakistan.

- Impact of promulgation of 18th constitutional amendment in June 2011 and dissolution of Federal Ministry of Health, Govt. of Pakistan.

- Depiction of current clinical and pharmaceutical care of patient i.e. prescription reviewing, therapeutical monitoring, patient's counseling and drug information.

- Envision of academic situation, to determine an integrated opponent lobby in academic institutions and in professional body of Pakistan Pharmacists Association (PPA). They have good control and connection with Drug Regulatory Authority (DRAP), Pharmacy Council of Pakistan (PCP), Higher Education Commission (HEC), provincial health departments, Drug Testing Laboratories (DTL's) and pharmaceutical manufacturers.

- Justification of an appropriate intervention of government agencies, health authorities, and professional associations in clinical settings.

- Narration of collective effort needed to introduce the therapeutical drug monitoring, phramcovigilance, prescription review and patient's counseling to mitigate the mortalities. It may potentially work like a safety valve and assure the correct medication at right time, right dose through proper route.

\section{About Authors}

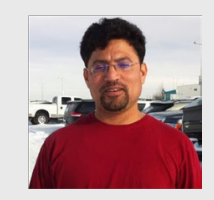

I was awarded the Ph.D degree in Microbiology by the Quid -I-Azam University, Islamabad. While; the degrees of M. Phil (Pharmacology) and Bachelor of Pharmacy were awarded two different Pakistani universities-University of Agriculture, Faisalabad, and University of the Punjab, Lahore, Pakistan. I have more than thirteen year's research, academic and professional experience along with exceptional exposure of miscellaneous biological techniques. I have good command over his disciplines of pharmacological, clinical pharmacy, epidemiology, microbiological and pharmaceutical biotechnology. Moreover; I have sufficient teaching experience to the student of Pharm D and M.Phil in different universities along with other professional expertise includes drug design, manufacturing, marketing and product development. 


\section{REFERENCES}

1. Mushirul Hasan, Sahdev Vohra. Punjab then and now, 1846-1999, The Partition Omnibus. Oxford: Delhi: Indian Publishers Distributors; 2000. p. 132.

2. Azhar S, Hassali MA, Ibrahim MIM, Ahmad M, Shafie AA. The role of pharmacists in developing countries: the current scenario in Pakistan. Hum Resour. Heal. 2009; 7(1): 54.

3. Butt ZA, Gilani AH, Nanan D, Sheikh AL, White F. Quality of pharmacies in Pakistan: a cross-sectional survey. Int J. Quality Health Care 2005; 17(4): 307-13.

4. Basak SC, Van Mil JW, Sathyanarayana D. Community Pharmacy Practice in India: Past, Present and Future. Southern Med Rev. 2009; 2(1): 11-4.

5. Stenson B, Syhakhang L, Lundborg CS, Eriksson B, Tomson G. Private pharmacy practice and regulation. A randomized trial in Lao PDR. Int $\mathrm{J}$ Technol Assess Health Care 2001; 17(04): 579-89.

6. Summers RS, Kruger $\mathrm{CH}$. Impact of training in drug supply management (DSM) on DSM, dispensing practice and patient knowledge and care at primary health care clinics. ICIUM, Chang Mai; 2004.

7. Ahmed SR, Bhutta ZA. A survey of paediatric prescribing and dispensing in Karachi. J Pak Med Assoc. 1990; 40(6): 126-30.

8. Sunderland B, Burrows S, Joyce A, McManus AA, Maycock B. Rural pharmacy not delivering on its health promotion potential. Aust. J. Rural Health 2006; 14(6): 116-9.

9. Kafle KK, Gartoulla RP, Pradhan YM, Shrestha AD, Karkee SB, Quick JD. Drug retailer training: experiences from Nepal. Soc Sci Med. 1992; 35(8): 1015-25.

10. Sunderland B, Burrows S, Joyce A, McManus AA, Maycock B. Rural pharmacy not delivering on its health promotion potential. Aust. J. Rural Health 2006; 14(3): 116-9.

11. Welch WP, Cuellar AE, Stearns SC, Bindman AB. Proportion of physicians in large group practices continued to grow in 2009-11. Health Aff (Millwood) 2013 Sep; 32(9): 1659-66.

12. Bert-Jaap Koops, et al. Starting Points for ICT Regulations, Deconstructing Prevalent Policy One-liners. Cambridge University Press, Cambridge; 2006, p. 81.
13. Butt ZA, Gilani AH, Nanan D, Sheikh AL, White F. Quality of pharmacies in Pakistan: a cross-sectional survey. Int J Qual Health Care 2005 Aug; 17(4): 307-13.

14. Azhar S, Hassali MA, Mohamed Ibrahim MI, Saleem F, Siow Yen L. A survey evaluating nurses perception and expectations towards the role of pharmacist in Pakistan's healthcare system. J Adv Nurs. 2012 Jan; 68(1): 199-205.

15. Kauhl B, Pilot E, Rao R, Gruebner O, Schweikart J, Krafft T. Estimating the spatial distribution of acute undifferentiated fever (AUF) and associated risk factors using emergency call data in India. A symptom-based approach for public health surveillance. Health Place 2015 Jan; 31: 111-9.

16. Hassel K, Seston L. Developing an RD agenda for pharmacy workforce research. IJOPP. 2001; 19(S1): R54.

17. Xinhua. Malaysia likely to meet WHO pharmacist-to-population standard Malaysian Journal of Pharmacy 2017; 16: 17.

18. Knapp DA. Professionally determined need for pharmacy services 2020. American Journal of Pharmacy Education 2002; 66(4): 421-9.

19. Doloresco F, Vermeulen LC. Global survey of hospital pharmacy practice. Am J Health Syst Pharm. 2009 Mar 1; 66(5 Suppl 3): S13-9.

20. Cooksey JA, Knapp KK, Walton SM, Cultice JM. Challenges to the pharmacist profession from escalating pharmaceutical demand. Health Aff (Millwood) 2002 Sep-Oct; 21(5): 182-8.

21. Passmore PR, Kailis SG. In pursuit of rational drug use and effective drug management: clinical and public health pharmacy viewpoint. Asia Pac $J$ Public Health 1994; 7(4): 236-41.

22. Khatri N, Gupta V. Effective implementation of health information technologies in U.S. hospitals. Health Care Manage Rev. 2014 Aug 12; [Epub ahead of print] PubMed PMID: 25120194. http://www.ncbi.nlm.nih. gov/pubmed/25120194\#

23. Hassel M, Eden. Workforce update-Joiners, leavers, and practising and nonpractising pharmacists on the 2005 register. The Pharmaceutical Journal 2006; 276(1): 40-2. 